\title{
Beauty of Energy-saving Makes You Impulsive! A Study on the Relationship between Product Aesthetics and Consumers' Impulsive Purchase Intention
}

\author{
Shansheng Yang ${ }^{1 *}$, Meihui Ji ${ }^{1}$, Jingyi Wang ${ }^{1}$ \\ ${ }^{1}$ School of Business Administration, Guangdong University of Finance and Economics University, 21 Luntou Road, Guangzhou 510320, \\ China
}

\begin{abstract}
Appearance design greatly affects the influence of products on consumers, and product aesthetics plays an increasingly important role in consumers' purchasing behavior. This article constructs a model of the influence of product aesthetics on consumers' impulsive purchase intention, and puts forward corresponding hypotheses on this basis. Finally, the model and hypotheses are tested and revised through empirical methods. The data of this research shows that the aesthetic design level of products positively affects consumers' impulsive purchase intentions, and positive emotions play an intermediary role between the two. At the same time, through analysis, this research confirms that consumers' CVPA levels have an impact on products. Green stands for energy saving, and consumer behaviors that are conducive to reducing consumer spending and environmentally friendly can be favored. These can make consumers think of beautiful things, thereby enhancing impulsive consumption behavior. The relationship between aesthetics and consumers' impulsive purchase intention has a moderating effect.
\end{abstract}

\section{Introduction}

More and more scholars have turned their research attention to the field of product aesthetics (for example, [1-3]). But so far, no scholar has linked product aesthetics with consumers' impulsive purchase intentions. This study considers that when consumers are individuals with different levels of visual aesthetics (that is, when consumers have different levels of CVPA), the positive relationship between product aesthetics and consumers' impulsive purchase intentions will result A certain influence, and the internal mechanism and boundary conditions are explored accordingly.

Based on this, this research is mainly to explore the relationship between product aesthetics and consumers' impulsive purchase intention, and to explore the internal mechanism and boundary conditions accordingly. Therefore, this research is related to product aesthetics. The enrichment and expansion of theories also have enlightening significance for the formulation of related marketing strategies for enterprises.

\section{Main variables}

We all know that products that are good for ourselves or the society will prompt us to buy, such as energy-saving and environmentally friendly products. The visual aesthetics in product design can be used as a very important factor to promote the sales of enterprise products. This is because, in the field of product consumption, there is a very important connection between the aesthetic design of the product and the aesthetic experience of consumers (for example, [1], [4]).

Impulse buying behavior is a subjective and unplanned buying behavior triggered by the stimulation of some factors during the whole process of consumers' purchase.

Through sorting and analysis, it can be found that relevant influencing factors can be mainly divided into three categories: individual characteristics of consumers, situational factors, and marketing stimuli. This research is mainly based on the characteristics of the product itself, exploring the influence of the aesthetic design level of the product on the consumer's impulsive purchase intention, and further exploring the internal mechanism.

As Watson (1988), psychologists usually divide emotions into positive emotions and negative emotions according to their pleasantness (for example, [6]). Among them, positive emotions represent joy, happiness, and happiness.

In Bloch's research, the centrality of product visual aesthetics (CVPA) refers to the overall importance of the visual aesthetics of the product to a certain consumer in relation to the product (for example, [5]). The difference in the level of individual consumers' response to product aesthetic design may be an important factor in their impulse purchase.

The scale developed by Bloch et al. (2003) is widely accepted by everyone (for example, [5]). When studying the central position of product visual aesthetics, through a 
lot of work, the central position of product visual aesthetics was conceptualized and developed. A scale is used to measure individual differences among consumers.

\section{Research hypotheses and model}

\subsection{Theoretical basis}

The "Stimulus-Organic-Response" theory (SOR theory) proposes that the stimulus provided by the external environment has an effect on the individual's inner mental state, which in turn causes the individual's behavioral response.

\subsection{Research hypothesis}

\subsubsection{The Influence of Product Aesthetics on Consumers' Impulsive Purchase Intention}

Actually, product aesthetics has a negative impact on consumers' price sensitivity. Specifically, when a product is more attractive, consumers are less price sensitive to the product. This in turn affects consumers' willingness to purchase the product. Not only that, but consumers are also willing to pay higher prices for highly aesthetic products (for example, [7]). Reimann (2010) showed that the aesthetic design of the product is an integral part of the product (for example, [2]). It can trigger many positive emotional and behavioral responses from consumers. Based on this, the following hypotheses are proposed:

$\mathrm{H} 1$ : Aesthetics of energy-saving product is positively affecting consumers' impulsive purchase intentions.

\subsubsection{The mediating role of positive emotions}

Compared with products with low aesthetics, products with more beautiful appearance can often gain some additional advantages (for example, [1]). On the other hand, the higher the intensity of the positive emotions generated by consumers after stimulation, the stronger their impulse purchase willingness and the easier it is to make impulse purchases.

The SOR theory points out that the stimulus in the external environment that consumers face will have an effect on their inner psychological state, which in turn will cause individual consumer behavioral responses. Based on this, this research proposes the following hypotheses:

$\mathrm{H} 2$ : Positive emotions play a mediating role between product aesthetics and consumers' impulsive purchase intentions.

\subsubsection{The modulating role of CVPA}

Individual consumers with high CVPA pay more attention to the aesthetic design of products than consumers with low CVPA, and the degree of visual beauty of the product will affect the consumer's experience of the product (for example, [5]). In addition, consumers with high CVPA often believe that contact with beautiful objects has a positive impact on them and can bring them more positive emotional experiences. Based on this, this research proposes the following hypotheses:

H3: Consumers' CVPA positively regulates the relationship between product aesthetics and consumers' positive emotions.

\section{Research model}

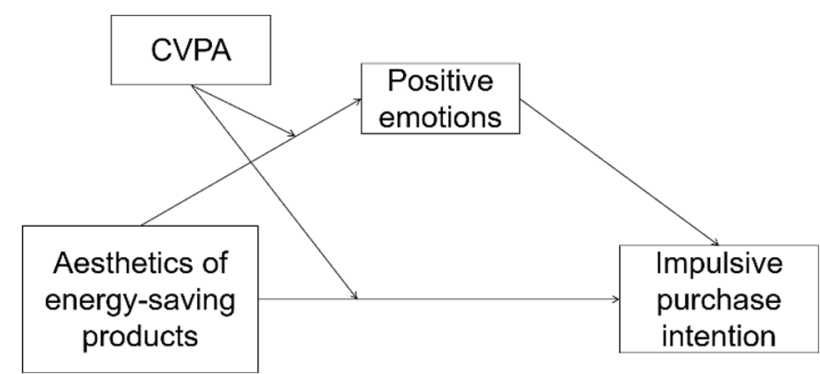

Fig. 1. Research model.

\section{Experiment and analysis}

Two experiments were conducted in this study. The measurement items of the first experiment are mainly composed of two parts. The first part is used to measure the aesthetic design level of the displayed pictures, and the second part is used to measure the consumer's impulsive purchase intention. The measurement items of the second experiment are mainly divided into four parts. The first part is used to measure the consumer's CVPA level, the second part is used to measure the product aesthetic design level of the displayed pictures, and the third part is used to measure Consumers' positive emotions, the fourth part measures impulsive purchase intentions. At the same time, we designed items such as age, gender, income, in order to analyze demographic characteristics. We have made appropriate adjustments to the semantic connotations, expression habits and usage of the measurement items used. All measurement items used Likert's 7-point scale.

\subsection{Experiment 1: The influence of product aesthetics on consumers' impulsive purchase intention}

This part is an empirical study on the influence of product aesthetics on consumers' impulsive purchase intention, namely test $\mathrm{H} 1$. In this part, the data is obtained by distributing the questionnaire and recycling the questionnaire, and then using SPSS23.0 to analyze and process the data collected by the questionnaire, and finally get the corresponding experimental results.

\subsubsection{Experimental design and sample selection}

The main purpose of this experiment is to verify Hypothesis 1. A single-factor experiment design is adopted. The independent variable is the product aesthetics, and the dependent variable is the consumer's impulsive purchase intention. In this experiment, 80 college students were recruited as the main experimental 
subjects. Among them, male subjects accounted for $30.56 \%$. Invalid samples were excluded. A total of 72 valid experimental data were collected.

In this study, the most commonly used Cronbach's Alpha coefficient method was used to measure the reliability of items in the relevant scales in the questionnaire. The higher the reliability coefficient, the greater the credibility of the items on the scale. We can see from Table 1 that the Cronbach's $\alpha$ coefficient of the Product Aesthetics Scale is 0.905, and the Cronbach's $\alpha$ coefficient of the Consumer Impulsive Purchase Intention Scale is 0.912 , indicating that each item has good internal reliability.

Table 1. Reliability analysis result of experiment 1.

\begin{tabular}{cc}
\hline Variable & Coefficient of Cronbach's Alpha \\
\hline $\begin{array}{c}\text { Product Aesthetics } \\
\text { Scale }\end{array}$ & 0.905 \\
$\begin{array}{c}\text { Impulsive Purchase } \\
\text { Intention Scale }\end{array}$ & 0.912 \\
\hline
\end{tabular}

Table 2. Analysis on the Influence of Product Aesthetics on Consumers' Impulsive Purchase Intention.

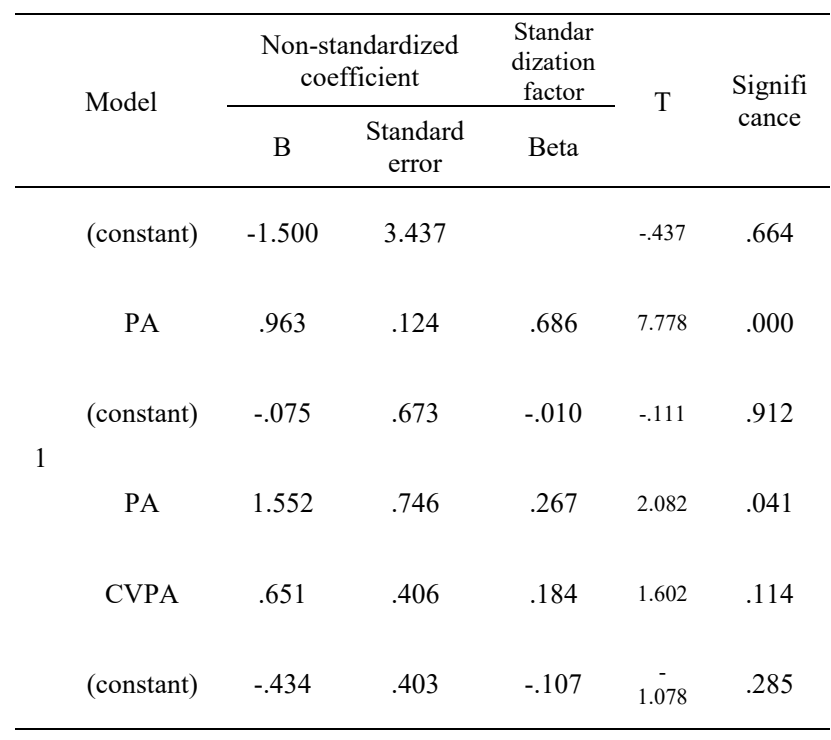

Through the analysis of the output results, it can be found that the aesthetic design level of the product does have a significant impact on consumers' impulsive purchase intention $(p=0.000<0.05)$. Specifically, the average value of consumers' impulsive purchase intentions for products with low aesthetics is lower than that for products with high aesthetics. This shows that for products with low aesthetics, consumers' willingness to purchase products with high aesthetics is stronger. $\mathrm{H} 1$ is verified.

\subsubsection{Experiment 2: The mediating role of positive emotions and the regulatory role of CVPA}

In this part, it is mainly for further verification of $\mathrm{H} 1$, and corresponding exploration of the internal mechanism and boundary conditions of product aesthetics affecting consumers' impulsive purchase intention, that is, to test $\mathrm{H} 2$ and $\mathrm{H} 3$.

In this experiment, a total of 110 college students were recruited as experimental subjects, of which male subjects accounted for $49.06 \%$. Through data screening, invalid samples were eliminated, a total of 98 valid experimental data were collected in this experiment.

By sorting out the corresponding data, the corresponding results are obtained. It can be seen that product aesthetics has a significant impact on consumers' impulsive purchase intention $(\mathrm{P}=0.000<0.05)$; in addition, it can be seen from Table 1 , The regression result of product aesthetics on positive emotion is $\mathrm{P}=0.000<0.05$, which passes the significance level test. Moreover, it shows that the regression result of positive emotions on impulsive purchase intention is $\mathrm{P}=0.000<0.05$, and the coefficient $B$ in model 2 is smaller than the coefficient $B$ in model 2, indicating that the mediating effect of positive emotion is significant, and it is Partial mediation effect. Therefore, $\mathrm{H} 2$ is verified.

In order to explore the boundary conditions of the influence of product aesthetics on consumers' impulsive purchase intention, this experiment also performed regression analysis on the collected data to test the moderating effect of the variable CVPA.

Table 3. SPSS regression analysis output results

\begin{tabular}{|c|c|c|c|c|c|}
\hline \multirow{2}{*}{ Model } & \multicolumn{2}{|c|}{$\begin{array}{c}\text { Non-standardized } \\
\text { coefficient }\end{array}$} & \multirow{2}{*}{$\begin{array}{c}\begin{array}{c}\text { Standa } \\
\text { rdizati } \\
\text { on }\end{array} \\
\text { factor }\end{array}$} & \multirow{2}{*}{$\mathrm{T}$} & \multirow{2}{*}{$\begin{array}{c}\text { Sign } \\
\text { ifica } \\
\text { nce }\end{array}$} \\
\hline & B & $\begin{array}{l}\text { Standard } \\
\text { error }\end{array}$ & & & \\
\hline (constant) & 3.807 & 1.196 & & 3.182 & .002 \\
\hline PA & 1.022 & .119 & .659 & 8.573 & .000 \\
\hline (constant) & 2.728 & 1.152 & & 2.368 & .020 \\
\hline PA & .672 & .143 & .433 & 4.685 & .000 \\
\hline CVPA & .083 & .021 & .358 & 3.868 & .000 \\
\hline (constant) & 2.950 & 1.139 & & 2.590 & .011 \\
\hline $\mathrm{PA}$ & .234 & .258 & .151 & .906 & .367 \\
\hline CVPA & .084 & .021 & .361 & 3.972 & .000 \\
\hline PA*CVPA & .006 & .003 & .315 & 2.032 & .045 \\
\hline
\end{tabular}

By sorting out the corresponding data, the corresponding results are obtained. It can be seen from Table 1 that $\mathrm{P}=0.045<0.05$, which proves that CVPA has a certain regulatory effect. Therefore, the results show that $\mathrm{H} 3$ has been verified accordingly. 


\section{Analysis conclusion}

Research and analysis show that Aesthetics of energysaving product is more likely to stimulate consumers' impulsive purchase intentions. The more effort consumers feel that aesthetic products are invested, they will think that the product is better and easier to purchase impulsively. The products trigger consumers' positive aesthetic pleasure, and the aesthetic pleasure further affects consumers' hedonic perception, which in turn contributes to consumers' impulsive purchases. In addition, consumers with higher product aesthetic requirements are less affected by high-aesthetic products, which is not easy to stimulate consumers' positive emotions; consumers with lower product aesthetic requirements, that is, low CVPA, are more affected by product aesthetics. Therefore, the positive influence of product aesthetics on the positive emotions of consumers is weaker.

This study proves the mediating role of positive emotions between product aesthetics and consumer impulsive buying behavior. Based on the perspective of consumer psychology, this article explores the intermediary relationship between product aesthetics and impulsive buying behavior. From an individual point of view, different consumers will have different emotions when facing product aesthetics, and their degrees are not the same, but positive emotions better summarize the generality of consumers when facing product aesthetics. Mental state.

Many scholars at home and abroad are paying more and more attention to research related to product aesthetics, and many branches of research have emerged, basically from the perspective of consumer psychology affecting consumer behavior. The research in this article is theoretical in the research of product aesthetics and visual marketing. Promote the role.

This research enriches the manifestations of product aesthetics on consumers' impulsive buying behavior. Based on the vision in sensory marketing, it links consumer CVPA, positive emotions and product aesthetics to advance the research progress of visual marketing.

In general, we can consider making products related to energy-saving economy more aesthetic in the future, which can help consumers' positive associations and promote impulsive consumption.

\section{References}

1. H. Leder, B. Belke, A. Oeberst, D. Augustin, Bir. J. Psyc 95, 489-508 (2004)

2. M. Reimann, J. Zaichkowsky, C. Neuhaus, T. Bender, B. Weber, J Cons Psyc 20, 431-441 (2010)

3. F. Wu, A. Samper, A.C. Morales, G. Fitzsimons, J Cons Rese, 45, 126-147 (2017)

4. L. Dongjin, L. Yan, W. Ruijuan, A Psyc Sci, 21, 336346(2013)

5. P.H. Bloch, F.F. Brunel, D.J. Arnold, J Cons Rese, 29, 551-565(2003)

6. D. Watson, L.A. Clark, A. Tellegen, J Pers Soc
Psychol, 54, 1063-1070(1988)

7. Yeung, Cwm, R. S. Wyer, J Cons Rese, (2004). 